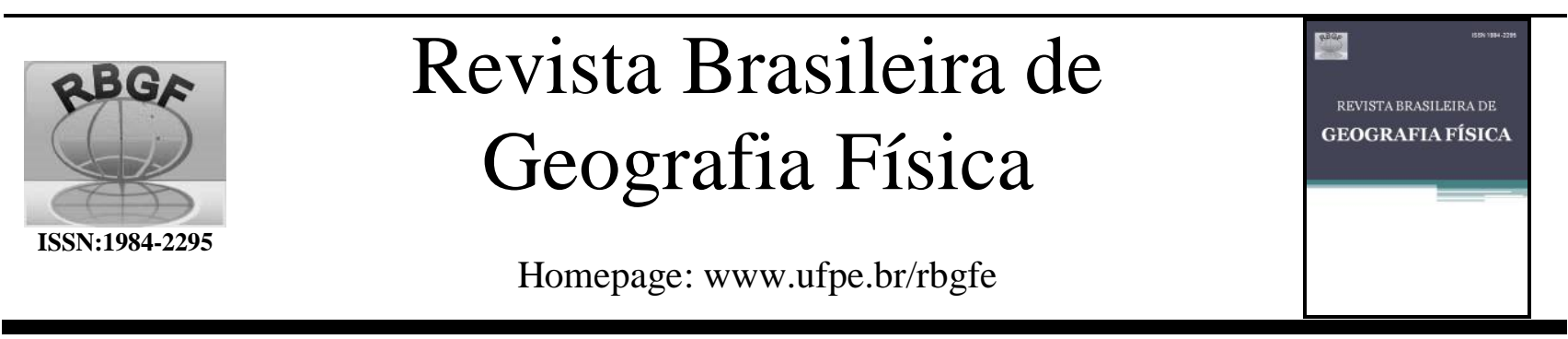

\title{
Comportamento vegetativo e qualidade tecnológica de cultivares de cana-de-açúcar submetidas ao estresse hídrico em condições semiáridas do Brasil
}

\author{
Anderson Ramos de Oliveira ${ }^{1}$, Marcos Brandão $\mathrm{Braga}^{2}$, Auriana Miranda Walker $^{3}$
}

${ }^{1}$ Pesquisador da Empresa Brasileira de Pesquisa Agropecuária - Embrapa Semiárido, Petrolina, PE, anderson.oliveira@embrapa.br. ${ }^{2}$ Pesquisador da Empresa Brasileira de Pesquisa Agropecuária - Embrapa Hortaliças, Brasília, DF, marcos.braga@embrapa.br. ${ }^{3}$ Analista Ambiental do Centro de Manejo de Fauna da Caatinga, Petrolina, PE, auriana_walker@hotmail.com.

Artigo recebido em 10/09/2015 e aceito em 30/11/2015.

\section{RESUMO}

A água tende a se tornar um recurso natural cada vez mais escasso em cenários de aumento da temperatura, principalmente, em regiões semiáridas. Por isso, no cultivo da cana-de-açúcar, buscam-se alternativas e técnicas que otimizem a eficiência da água. O objetivo deste estudo foi analisar as características biométricas e a qualidade tecnológica de sete cultivares de cana-de-açúcar: RB 96-1003, RB 94-3206, RB 72-454, RB 01-2018, VAT 90-212, RB 01-2046 e RB 92-579 submetidas a quatro lâminas de reposição hídrica: 40, 60, 80 e 100\%, baseadas na evapotranspiração da cultura. As avaliações foram realizadas em ciclo de cana soca de segunda folha, irrigada por gotejamento subsuperficial e consistiram na análise de altura, diâmetro do colmo, número de entrenós, número de perfilhos, ${ }^{\circ}$ Brix, percentual de açúcar bruto, pureza, fibra e açúcares redutores. Constatou-se que a altura máxima pode ser alcançada com menores lâminas de reposição de água; que o diâmetro do colmo e o número de entrenós são características mais relacionadas com o componente genético da cultivar e que o número de perfilhos é pouco influenciado pelas lâminas de reposição hídrica. Verificou-se que as cultivares de cana têm características tecnológicas do caldo que atendem aos padrões estabelecidos, com exceção da fibra que apresentou valor mais elevado do que o recomendado. As características biométricas e tecnológicas do caldo podem auxiliar na recomendação de cultivares mais tolerantes ao estresse hídrico e, consequentemente, com maior potencial de produção em cenários de aumentos de temperatura e economia de água.

Palavras-chave: eficiência no uso da água, cana soca, biometria, irrigação subsuperficial.

\section{Behavior vegetative and technological characteristics sugarcane cultivars under water stress in semi-arid conditions of Brazil}

\begin{abstract}
The water tends to become a natural resource increasingly scarce in temperature rise scenarios, especially in semi-arid regions. Therefore, the cultivation of sugarcane, seek to alternatives and techniques that optimize water efficiency. The objective of this study was to analyze the biometric features and the technological quality of seven cultivars of sugarcane: RB 96-1003; RB 94-3206; RB 72-454; RB 01-2018; VAT 90-212; RB 01-2046 and RB 92-579 submitted to four blades of fluid replacement: 40, 60, 80 and 100\%, based on crop evapotranspiration. The evaluations were performed in sugarcane ratoon cycle of second sheet, irrigated by subsurface drip and consisted of analysis of height, stem diameter, number of internodes, number of tillers, ${ }^{\circ}$ Brix, percentage of raw sugar, purity, fiber and reducing sugars. It was found that the maximum height can be achieved with lower water replacement blades; the stem diameter and the number of internodes are more characteristics related to the genetic component of the plant variety and the number of tillers is little influenced by the fluid replacement blades. It was found that sugarcane cultivars have technological characteristics of the broth that meet established standards, except that the fiber had a higher value than recommended. Biometric and technological characteristics of the juice can help in recommending more tolerant cultivars to water stress and thus more potential production scenarios temperature increases and water savings.

Keywords: efficient use of water, ratoon cycle sugarcane, biometrics, subsurface drip irrigation.
\end{abstract}




\section{Introdução}

Um dos aspectos mais importantes quando se analisam os cenários de mudanças climáticas diz respeito à disponibilidade de água para a irrigação. A água tem se tornado um recurso cada vez mais limitado e essa condição pode ser potencializada nos cenários de aumento da temperatura, notadamente em regiões semiáridas.

A agricultura demanda grandes quantidades de água para suprir as necessidades das plantas. Dentre os cultivos irrigados, destaca-se a cana-deaçúcar, por suas características responsivas à irrigação. As mudanças climáticas e seus efeitos na cultura da cana-de-açúcar são incertos e, por vezes, contraditórios. Segundo Gouvêa et al. (2009), as projeções climáticas para este século indicam a possibilidade de graves consequências para a humanidade, especialmente para a agricultura. De acordo com estes autores, o aumento da temperatura, em projeções climáticas até o ano de 2080, acarretará aumento na produtividade potencial da cana-de-açúcar, já que essa variável afeta positivamente a eficiência do processo fotossintético das plantas $\mathrm{C} 4$; entretanto, as alterações na radiação solar e na chuva terão menores impactos na produtividade. Assim, o aumento da produtividade potencial da cana-deaçúcar poderá compensar o efeito negativo causado pelo aumento projetado para cenários com maior restrição hídrica. Por outro lado, Carvalho et al. (2015) afirmam que apesar de a cana-de-açúcar ser uma cultura típica de clima quente e úmido e, portanto, bem adaptada ao clima em muitas regiões do Brasil, o rendimento potencial pode ser reduzido no futuro próximo (2014-2040) devido às mudanças climáticas, pois as altas temperaturas no Nordeste brasileiro promoverão aumentos nas taxas de evapotranspiração, reduzindo a quantidade de água disponível no solo, tornando o plantio de cana-de-açúcar cada vez mais difícil, com tendências de redução em áreas mais secas.

Atualmente, o Brasil é o maior produtor mundial da cultura, seguido por Índia e China, e também o maior produtor de açúcar e etanol de cana-de-açúcar, sendo responsável por mais de $50 \%$ do açúcar comercializado no mundo. A produção total na safra de $2014 / 2015$ foi de 634,8 milhões de toneladas, com produtividade de colmos de $70.495 \mathrm{~kg} \mathrm{ha}^{-1}$, açúcar de 35,56 milhões de toneladas e etanol de 28,68 bilhões de litros (Companhia Nacional de Abastecimento - Conab, 2015). Na região Nordeste, o cultivo da cana-deaçúcar se limitou, desde a colonização, às zonas litorâneas e ao Agreste, onde a precipitação possibilitava o desenvolvimento da cultura. Contudo, a produtividade sempre foi inferior à média nacional. Segundo informações da Conab, na safra de 2014/2015, a área cultivada com canade-açúcar foi da ordem de 979 mil ha, com produtividade média de $56.857 \mathrm{~kg} \mathrm{ha}^{-1}$, bem inferior à média nacional (Conab, 2015).

Para que o País continue liderando a produção e comercialização de cana-de-açúcar e seus derivados, serão necessários investimentos em pesquisas, as quais contemplem as projeções de aumento de temperatura provocadas pelas mudanças climáticas globais e as práticas e, ou os sistemas alternativos de adaptação e mitigação dos efeitos danosos das mudanças climáticas na cultura.

No Brasil, a prática da utilização de irrigação da cana, durante muitos anos, sempre esteve ligada à utilização de água em quantidades superiores às necessidades da cultura. Contudo, a pressão da sociedade por tecnologias mais sustentáveis impulsionou a agricultura de precisão e contribuiu significativamente para a adoção de técnicas com maior eficiência no uso da água (Azad et al., 2015).

$\mathrm{Na}$ cultura da cana-de-açúcar, o uso de ferramentas de precisão é cada vez mais demandado, a exemplo da utilização de sistemas de irrigação que proporcionam menores desperdícios de água. Ainda, os investimentos em tecnologia da irrigação (planejamento e implantação de projeto de irrigação, uso de sistema de irrigação localizada do tipo gotejamento superficial e subsuperficial, automatização de sistema de irrigação, uso da fertilização via sistema de irrigação fertirrigação) e o lançamento de novas variedades de cana-de-açúcar (cultivares com maior potencial produtivo e maior tolerância a estresses), bem como a combinação da irrigação com variedades adaptadas aos diversos ambientes edafoclimáticos, proporcionam incrementos na qualidade do caldo e na produção de colmos, no rendimento bruto de açúcar e no rendimento bruto de álcool (Farias et al., 2008; Carvalho et al., 2009).

Considerando a região semiárida do Nordeste, a atividade sucroalcooleira seria inviável sob condições normais de precipitação, pois a cana-de-açúcar, em seu sistema de produção, consome entre 1.500 e $2.000 \mathrm{~mm}$ de água por ciclo anual, para alcançar produtividade em torno de 100 a $150 \mathrm{t} \mathrm{ha}^{-1}$ (Doorenbos e Kassam, 1979) e as médias de precipitação da região são muito inferiores, além de se 
apresentarem mal distribuídas. De forma resumida, pode-se dizer que o clima da região Semiárida se caracteriza por apresentar temperaturas altas (acima dos $20^{\circ} \mathrm{C}$ de médias anuais) e precipitações escassas (280 a $800 \mathrm{~mm}$ ). Sendo assim, o balanço hídrico dessa região apresenta deficiência hídrica, porque o potencial de evapotranspiração é maior do que as precipitações e, além disso, o período chuvoso é concentrado em apenas três ou quatro meses (Araújo, 2011), sendo os demais meses de longa estiagem. Contudo, nas últimas décadas, no Submédio do Vale do São Francisco, a cultura da cana-de-açúcar destaca-se em produtividade, devido à irrigação plena durante todo o ciclo de cultivo, permitindo que a mesma expresse todo o seu potencial e, consequentemente, possibilite produtividades superiores à média nacional. Apesar de a área ser ainda reduzida, segundo informações da Rede Interuniversitária para o Desenvolvimento do Setor Sucroalcooleiro (RIDESA, 2010), uma das cultivares de cana-deaçúcar (RB-92579) plantadas na Usina Agrovale, na Bahia, em área de 60 ha sob irrigação plena, atingiu produtividade de $260 \mathrm{t} \mathrm{ha}^{-1}$, considerado um recorde mundial de máxima produtividade em área comercial.

Os altos índices de produtividade são alcançados em áreas onde se pratica a maior tecnologia de precisão, notadamente no que se refere à utilização de sistemas de irrigação localizados e aplicação de nutrientes via fertirrigação. $O$ manejo da irrigação por gotejamento subsuperficial é uma das práticas mais difundidas, atualmente, para o cultivo irrigado da cana-de-açúcar. Tal prática está atrelada a diversas vantagens, tais como: redução na lixiviação de nitrato se comparado à irrigação por superfície, maior eficiência no controle de plantas daninhas, menor incidência de doenças, por evitar o contato da água com a parte aérea e a formação de microambientes propícios ao desenvolvimento de bactérias e fungos, maior flexibilidade no processo de colheita, menor estresse hídrico da planta, devido à aplicação de água próxima à zona radicular, possibilidade de se aplicar nutrientes via água de irrigação (fertirrigação), redução das perdas de mangueiras danificadas por máquinas e equipamentos e, a principal vantagem, aumento da produtividade da cultura (Hussain et al., 2010; Pires et al., 2014).

Aliada a esta importante ferramenta de precisão, pode-se optar por cultivares de cana-deaçúcar que apresentem melhor resposta de desenvolvimento, utilizando-se menores lâminas de irrigação. Segundo Basnayake et al. (2012), alguns clones de cana-de-açúcar podem manter a produtividade relativamente alta, mesmo se submetidos a condições de estresse moderado. Características de crescimento como perfilhamento e comprimento do colmo podem ser úteis para a detecção precoce de estresse hídrico na cultura, bem como na seleção de cultivares que apresentem maior tolerância ao estresse (Zhao et al., 2013).

Hemaprabha et al. (2013), estudando o potencial de tolerância de genótipos elite e progênies de cana-de-açúcar à seca, verificaram que maiores reduções são observadas nas características biométricas de comprimento de entrenós, altura, biomassa e teor de sacarose quando as cultivares são submetidas ao estresse hídrico. Por outro lado, as características de diâmetro do colmo e número de entrenós apresentam baixa variação, indicando que reduções na altura e encurtamento de entrenós são características que apresentam correlação positiva com a produção e que devem ser considerados confiáveis em uma seleção de cultivares mais promissoras às diferentes condições de estresse hídrico.

Além de aspectos relacionados ao desenvolvimento da cultura, tais como altura, diâmetro, número de folhas, número de perfilhos por metro linear e produtividade, dentre outros, num processo de avaliação de cultivares de canade-açúcar com maior potencial de produção sob manejo de restrição hídrica, deve-se analisar a qualidade tecnológica do caldo produzido, pois estresses hídricos podem alterar as características químicas do caldo, reduzindo a qualidade do mesmo (Wiedenfeld, 2000; Vasconcelos, 2013).

A qualidade tecnológica do caldo de canade-açúcar para a produção de etanol é um dos aspectos mais relevantes que deve ser considerado em qualquer sistema de manejo, pois alterações na qualidade da matéria prima produzida poderão causar o descarte do material no momento do processamento na usina. De acordo com Figueiredo et al. (2008), um processo com alto rendimento e um produto final de qualidade está diretamente relacionado com a qualidade da matéria-prima, a qual deve ser fresca, livre de impurezas e sem o ataque de pragas e doenças. Assim, além de avaliações biométricas para a seleção de cultivares com maior tolerância ao estresse hídrico, são necessárias que sejam avaliadas as características tecnológicas destas cultivares, a fim de que não ocorram alterações significativas que comprometam a matéria-prima. 
De acordo com Horii (2004), a composição química e tecnológica da cana-de-açúcar varia em função de muitos fatores, tais como: variedade, espaçamento e perfilhamento, idade ou corte, estágio de maturação, clima ao longo do ciclo, propriedades físicas e químicas do solo, adubação, tratos culturais, rápidofechamento das touceiras, sanidade, brotação da soqueira, florescimento e com o manejo da irrigação. Entre as variáveis comumente avaliadas, citam-se: o teor de sólidos solúveis - ${ }^{\circ}$ Brix, a fibra industrial na cana-deaçúcar, a pureza do caldo, a percentagem de açúcar bruto - PCC e os açúcares redutores - AR.

Segundo Leme Filho (2005), o ${ }^{\circ}$ Brix corresponde ao teor percentual, em massa, de sólidos solúveis do caldo de cana. Dentre os sólidos solúveis, destacam-se, em importância e em quantidade, os açúcares (glicose, frutose e sacarose). Caldas (2005) relata que a determinação do teor de sólidos ( ${ }^{\circ}$ Brix) dissolvidos em uma solução é de suma importância, não apenas para o cálculo da pureza da matéria-prima e demais produtos da fabricação, mas também pelo seu uso nos balanços de massa e divisão de cana para produção de açúcar e etanol.

A glicose e a frutose, por apresentarem propriedade de reduzir, em meio alcalino e a quente, os íons cúpricos a cuprosos, são conhecidas como açúcares redutores (AR). A sacarose é o açúcar mais abundante, sendo representada pelo pol do caldo, contribuindo para a avaliação da percentagem de açúcar bruto PCC, que é um índice diretamente relacionado ao valor econômico da tonelada da cana, ou seja, para valores elevados deste índice têm-se preços da cana compatíveis no mercado (Assis et al., 2004).

A pureza demonstra a qualidade da matériaprima. Valores altos de AR (glicose e frutose) reduzem a pureza e se refletem em menor eficiência na recuperação da sacarose pela fábrica. A fibra, por sua vez, reflete-se na eficiência da extração da moenda, ou seja, quanto mais elevado o percentual de fibra da cana, menor será a eficiência da extração (Vian, 2013). Aumentos nos teores de fibra de cultivares de cana-deaçúcar, por ocasião do florescimento, dificultam a extração de caldo em moendas, reduzindo sua eficiência. Além disso, o teor de fibra possui relação negativa com o teor de açúcar (Marques et al., 2008). Ripoli e Ripoli (2004) propuseram indicadores da qualidade e valores recomendados para a cana-de-açúcar. Assim, os valores de pureza devem ser superiores a $85 \%$, a fibra deve estar entre 11 e $13 \%$ e os valores de AR devem ser inferiores a $0,8 \%$. Lima et al. (2001) esclarecem que a constituição do caldo da canade-açúcar apresenta de 78 a $86 \%$ de água, 10 a $20 \%$ de sacarose, 0,1 a $2,0 \%$ de açúcares redutores, 0,3 a $0,5 \%$ de cinza e 0,5 a $1,0 \%$ de compostos nitrogenados, sendo que o $\mathrm{pH}$ varia de 5,2 a 6,8 .

A integração entre as avaliações biométricas e as avaliações de qualidade tecnológica, num estudo de seleção de cultivares mais adaptadas a condições de estresse hídrico, poderá influenciar na escolha da cultivar para regiões tradicionais ou em expansão. $\mathrm{O}$ aspecto relevante reside no fato de se poder cultivar variedades que atinjam produtividades compatíveis ou semelhantes aos cultivos irrigados com $100 \%$ de reposição hídrica da lâmina de evapotranspiração, utilizando-se menores lâminas de irrigação. Isso implica em economia de água promovida pela redução de custos com a captação e distribuição da mesma, economia de energia (bombeamento e distribuição), proporcionando maior sustentabilidade ao sistema de produção sucroalcooleiro.

A suscetibilidade da cana-de-açúcar à deficiência hídrica é maior quando as plantas estão na fase de alongamento dos colmos, o que causa sérios prejuízos na produção de fitomassa $\mathrm{e}$ no rendimento da sacarose (Inman-Bamber e Smith, 2005). Contudo, algumas cultivares de cana-de-açúcar podem apresentar tolerância ao estresse hídrico e se desenvolverem satisfatoriamente bem, mesmo em condições de restrição no volume de água aplicado ou em períodos prolongados de estiagem (Santos, 2011; Camargo, 2013). Ainda de acordo com InmanBamber e Smith (2005), a cana-de-açúcar apresenta variação genotípica quanto à tolerância ao déficit hídrico. Assim, algumas cultivares podem demonstrar maior tolerância do que outras num mesmo ambiente de produção. Em estudo desenvolvido por Machado et al. (2009), com o genótipo IACSP 96-2042, verificou-se que, independentemente da fase fenológica, o genótipo é tolerante ao déficit hídrico, pois mantém a produção de fitomassa, mesmo com redução das trocas gasosas.

De acordo com Pincelli (2010), a tolerância ao déficit hídrico se manifesta geralmente de quatro formas: limitação no crescimento, adaptações morfológicas, adaptações fisiológicas e alterações metabólicas. Um exemplo de tolerância é apresentado por Pincelli e Silva (2012), que verificaram as respostas de variáveis morfológicas de quatro cultivares comerciais de cana-de-açúcar sob diferentes regimes hídricos e 
concluíram que as cultivares SP 81-3250 e SP 832847, quando submetidas à deficiência hídrica por período prolongado no início do desenvolvimento, apresentam maior largura de folhas, menor dano ao número de folhas verdes e área foliar; aumento na densidade estomática nas superfícies adaxial e abaxial foliares, e maior produção de massa de matéria seca, sendo, assim, consideradas tolerantes. Holanda et al. (2014) também concluíram que as variáveis morfológicas são eficientes em diferenciar as cultivares tolerantes e suscetíveis ao estresse hídrico.

O uso de atributos biométricos (número de perfilhos, altura de plantas, diâmetro de colmos, etc.) e tecnológicos para auxiliar na identificação de genótipos mais tolerantes ( ${ }^{\circ} \mathrm{Brix}$, pol do caldo, açúcar total recuperável, pureza, fibra, etc.) pode ser eficiente na diferenciação dos tratamentos irrigado e sequeiro, indicando que as cultivares respondem de maneira diferenciada à aplicação de água (Arantes, 2012).

Assim, este trabalho teve como objetivo analisar as características biométricas e a qualidade tecnológica do caldo de sete cultivares de cana-de-açúcar submetidas a diferentes lâminas de reposição hídrica da evapotranspiração da cultura em cultivos irrigados por gotejamento subsuperficial em ciclo de cana soca de segunda folha, no Semiárido brasileiro.

\section{Material e Métodos}

O estudo foi desenvolvido no Campo

Experimental de Bebedouro, pertencente a
Embrapa Semiárido, em Petrolina, PE, (latitude $09^{\circ} 09^{\prime} \mathrm{S}$ e longitude $42^{\circ} 22^{\prime} \mathrm{W}$ ), em ciclo de cana soca de segunda folha (ressoca).

O clima da região, segundo Köppen, é do tipo BSWh, tropical semiárido, com chuvas concentradas entre os meses de novembro e abril, com precipitação média anual em torno de 540 $\mathrm{mm}$, irregularmente distribuída.

As condições climáticas foram monitoradas durante todo o período de condução do experimento, sendo o período caracterizado por estiagem severa, com precipitação de apenas 138 $\mathrm{mm}$, em um intervalo de 12 meses; umidade relativa média de $55 \%$, temperatura média de 26,4 ${ }^{\circ} \mathrm{C}$ e evaporação média de $7,9 \mathrm{~mm}$ registradas na Estação Agrometeorológica de Bebedouro, pertencente à Embrapa Semiárido (Figura 1). A evapotranspiração média da cultura é de $4,7 \mathrm{~mm}$ $\mathrm{dia}^{-1}$ (Silva et al., 2012b).

A radiação solar global média foi de 480,92 ly/dia, a insolação média mensal (horas) foi de 7.483 horas e a velocidade média mensal do vento à altura de 2,0m foi de 215,1417 km/dia.

Para a descrição e classificação do solo da área experimental foi aberta uma trincheira com 1 $\mathrm{m}$ de profundidade, $1 \mathrm{~m}$ de largura e $1 \mathrm{~m}$ de comprimento, em área referência, próxima à área de plantio. A distinção da classe de solo foi baseada nas características e propriedades do solo (EMBRAPA, 2012), possibilitando classificá-lo como Latossolo Vermelho-Amarelo eutrófico.

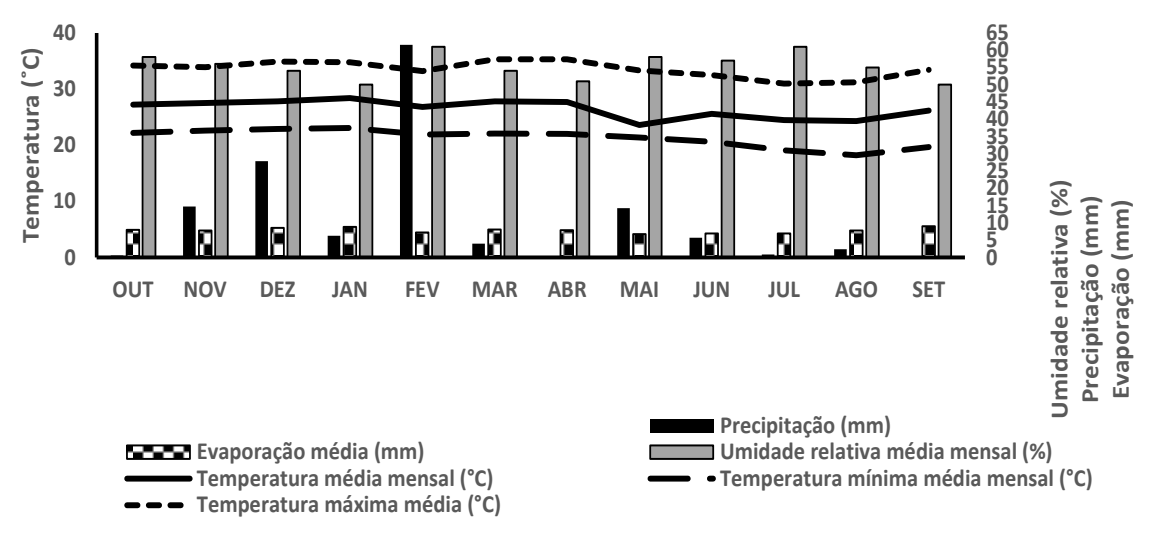

Figura 1. Registros climáticos durante o período experimental - Estação Agrometeorológica de Bebedouro Petrolina - PE.

Adotou-se o delineamento experimental em blocos casualizados, tipo fatorial, com sete cultivares de cana-de-açúcar: RB 96-1003, RB 94-
3206, RB 72-454, RB 01-2018, VAT 90-212, RB 01-2046 e RB 92-579 e quatro lâminas de reposição hídrica: 40, 60, 80 e $100 \%$ da

Oliveira; A. R. O.; Braga, M. B.; Walker, A. M. 
evapotranspiração da cultura (ETc) em três repetições.

As cultivares utilizadas no estudo foram cedidas pela Usina Agrovale S.A. - Juazeiro BA. Três destas cultivares apresentam características singulares, são elas: RB 72454, RB 92579 e VAT 90-212. A RB72454 é, provavelmente, a variedade de cana-de-açúcar mais plantada no mundo, possui colmos de bom diâmetro, de boa altura e de elevado peso, sem rachaduras e eretos ou semieretos nas condições normais. As touceiras não apresentam perfilhos tardios, razão por que os colmos são bastante uniformes, boa produtividade agrícola, boa capacidade de germinação, maturação média, com alto teor de sacarose e baixo índice de chochamento. A RB 92579 apresenta crescimento ereto, arquitetura foliar com pontas curvas, copa de volume regular e tonalidade intermediária, difícil despalha, ótima brotação na planta e na soca, alto perfilhamento em planta e soca, velocidade lenta de crescimento, alta produtividade agrícola nas quatro primeiras folhas, alto teor de açúcares totais recuperáveis (ATR), maturação média e médio teor de fibra (RIDESA, 2010). A VAT 90-212, por sua vez, apresenta boa brotação de socaria, regular volume de folhas, crescimento ereto, fácil despalha, médio diâmetro do colmo, colmo de cor roxa, gema obovada, boa produtividade agrícola, baixo florescimento, alto teor de sacarose, médio teor de fibra, média maturação, médio período útil industrial (PUI) e média exigência com relação à fertilidade do solo.

As plantas foram cultivadas considerandose a disponibilidade hídrica de $100 \%$ da ETc até 90 dias após a colheita da cana soca de primeira folha, período correspondente às fases de germinação e perfilhamento da cultura. Logo após, as parcelas sorteadas com menores lâminas de reposição hídrica foram submetidas ao estresse até um mês antes da colheita, que ocorreu aos 360 dias. Foram instaladas baterias de tensiômetros (três tensiômetros/bloco/lâmina de reposição hídrica da ETc) nas profundidades de 20, 40 e 60 $\mathrm{cm}$ na área, próximos à cultivar RB 72-454 (considerada padrão em estudos de cana-deaçúcar), para aferir a tensão com que a água é retida pelo solo e, indiretamente, determinar o teor de água no solo (umidade do solo), tendo a finalidade de monitorar com maior precisão o manejo da irrigação.

Os tratamentos de estresse hídrico foram baseados na Evapotranspiração Real da Cultura (ETc), obtida pela equação 1:

$$
E T c=\text { Kc } x \text { ETo }[1]
$$

Em que:

ETc = evapotranspiração da cultura da cana-de-açúcar ( $\mathrm{mm} / \mathrm{dia})$;

$\mathrm{Kc}=$ coeficiente da cultura da cana-deaçúcar (adimensional);

ETo = evapotranspiração da cultura de referência $(\mathrm{mm} / \mathrm{dia})$.

Para o cálculo da ETc, levaram-se em consideração as fases fenológicas da cultura. Assim, utilizou-se o Kc sugerido pela FAO, em que, na fase inicial do cultivo, o valor é de 0,4 , no máximo de desenvolvimento da cultura, assumiu o valor de 1,25 e ao final do ciclo o $\mathrm{Kc}$ foi reduzido para 0,7, conforme Allen et al. (1998).

O sistema de irrigação adotado foi o gotejamento subsuperficial com emissores autocompensantes espaçados em $0,3 \mathrm{~m}$ entre si. Cada parcela foi constituída por nove fileiras duplas de plantio com $15 \mathrm{~m}$ de comprimento. As linhas duplas de plantio foram espaçadas em 0,4 $\mathrm{m}$, enquanto as linhas do sistema de gotejamento subsuperficial foram espaçadas entre si em 1,6 m, correspondendo a uma área de $192 \mathrm{~m}$ /2/parcela.

As cultivares foram fertirrigadas uma vez por semana, conforme a curva de absorção de nutrientes da cultura da cana-de-açúcar descrita por Bachchhav (2005) e também com base na recomendação de análise de solo. Para tanto, procedeu-se a coleta de amostras de solo, na profundidade de 0 a $20 \mathrm{~cm}$ em todas as parcelas experimentais.

As amostras de solo coletadas foram analisadas no Laboratório de Solos do Centro de Pesquisa Agropecuária do Trópico Semiárido (CPATSA), seguindo-se a recomendação de EMBRAPA (2006) e EMBRAPA (2012).

O teor de matéria orgânica do solo foi de $13,14 \mathrm{~g} \mathrm{~kg}^{-1}$. $\mathrm{O} \mathrm{pH}$ foi medido eletronicamente por meio de eletrodo combinado imerso em suspensão solo:líquido (água), na proporção de $1: 2,5$ e encontrou-se o valor de 6,4. O fósforo foi extraído utilizando-se a solução extratora

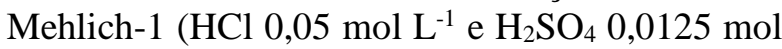
$\left.\mathrm{L}^{-1}\right)$, resultando em $32,28 \mathrm{mg} / \mathrm{dm}^{3}$ de P. Os cátions trocáveis, $\mathrm{Ca}^{2+}+\mathrm{Mg}^{2+}$,foram extraídos com $\mathrm{KCl} 1$ mol L ${ }^{-1}$ e determinados por titulação com EDTA $0,0125 \mathrm{~mol} \mathrm{~L}^{-1} \mathrm{em}$ presença do indicador negro de eriocromo, resultando, respectivamente em 1,5 e $1,2 \mathrm{cmolc} / \mathrm{dm}^{3}$.

A condutividade elétrica (CE) de $0,21 \mathrm{~d} / \mathrm{Sm}$ foi determinada no extrato da pasta de saturação com auxílio de condutivímetro digital. $\mathrm{O} \mathrm{Na}^{+}$ $\left(0,03 \mathrm{cmolc} / \mathrm{dm}^{3}\right)$ e o $\mathrm{K}^{+}\left(0,38 \mathrm{cmolc} / \mathrm{dm}^{3}\right)$ foram extraídos pela solução extratora Mehlich-1 e 
determinados por espectrofotometria de chama. $\mathrm{O}$ teor de alumínio trocável $\left(\mathrm{Al}^{3+}\right)$ foi de 0,05 cmolc/dm ${ }^{3}$ extraído com solução $\mathrm{KCl} 1 \mathrm{~mol} \mathrm{~L}^{-1} \mathrm{e}$ determinado volumetricamente com solução diluída de $\mathrm{NaOH}\left(0,025 \mathrm{~mol} \mathrm{~L}^{-1}\right)$ na presença de azul de bromotimol como indicador. A acidez potencial $(\mathrm{H}+\mathrm{Al})$ foi extraída com acetato de cálcio tamponado a pH 7,0 e determinada volumetricamente com solução de $\mathrm{NaOH}(0,1 \mathrm{~mol}$ $\mathrm{L}^{-1}$ ), em presença de fenolftaleína como indicador, cujo resultado foi de $2,31 \mathrm{cmolc} / \mathrm{dm}^{3}$. A capacidade de troca de cátions de $5,42 \mathrm{cmolc} / \mathrm{dm}^{3}$ foi obtida pela fórmula $\mathrm{CTC}=\mathrm{SB}+(\mathrm{H}+\mathrm{Al})$, a saturação por bases foi de $57 \%$ pela fórmula $\mathrm{V}=$ (SB/CTC).

Durante todo o período experimental foram adotadas medidas de controle de plantas daninhas, por meio de duas capinas manuais, que aconteceram até 90 dias após a colheita da cana soca de primeira folha abrangendo o período crítico de interferência das plantas daninhas à cultura. Foram realizados, ainda, monitoramentos de pragas e doenças a fím de evitar que a área sofresse prejuízos com insetos e patógenos, prevenindo-se, desta forma, interferências que pudessem confundir os resultados alcançados nos tratamentos de estresse hídrico.

Aos 120, 180, 270 e 360 dias (colheita da cana soca de segunda folha - ressoca) foram realizadas as avaliações biométricas de altura, diâmetro do colmo, número de entrenós e número de perfilhos. Escolheram-se três plantas, de forma aleatória, dentro da área útil, as quais foram identificadas por meio de uma fita. Para registrar o diâmetro do colmo, utilizou-se paquímetro digital e determinou-se a média, em milímetros, de três observações realizadas entre o quinto e o sexto entrenó das três plantas selecionadas, sendo que cada uma constituiu-se em uma repetição. Para avaliação da altura da planta, utilizou-se uma trena graduada e fez-se a medida da distância do solo até a lígula da última folha recém expandida. O número de entrenós foi obtido pela contagem direta dos entrenós das plantas identificadas. $\mathrm{O}$ número de perfilhos foi obtido por meio da divisão do número total de perfilhos computados nos cinco metros centrais de cada parcela e expressos em número de perfilhos por metro linear.

Para a análise das características tecnológicas do caldo, foram coletados cinco colmos de cada variedade em cada uma das parcelas experimentais, os quais foram conduzidos para o Laboratório de Análise Tecnológica da Usina Agrovale S. A., em
Juazeiro, BA, onde foram submetidos às análises de teor de sólidos solúveis ( ${ }^{\circ}$ Brix), pureza do caldo (Pureza), fibra na cana (Fibra), porcentagem de açúcar bruto (PCC) e açúcares redutores (AR), conforme metodologia do Sistema de Pagamento de Cana pelo Teor de Sacarose - SPCTS (CONSECANA, 2006).

A determinação do teor de sólidos solúveis do caldo ( ${ }^{\circ}$ Brix) foi realizada por refratômetro digital, com correção automática da temperatura, sendo o valor final expresso a $20{ }^{\circ} \mathrm{C}$.

$\mathrm{O}$ teor de sacarose aparente do caldo (pol) foi determinado por da meio equação 2:

$$
\mathrm{Pol}=\mathrm{Lpb} \times(0,2605-0,0009882 \times \text { Brix })
$$

em que:

Lpb - leitura sacarimétrica equivalente à de subacetato de chumbo

${ }^{\circ}$ Brix - teor de sólidos solúveis do caldo

O teor de fibra da cana foi determinado por meio da equação 3 :

Fibra $=(0,08 \times P B U)+0,876$

em que:

Fibra - teor de fibra da cana-de-açúcar

PBU - peso do bagaço úmido da prensa, $g$

A pureza do caldo foi determinada por meio da equação 4 :

Pureza $=100 \times\left(\right.$ Pol $^{\circ}$ Brix $) \quad[4]$

em que:

Pureza - pureza do caldo

Pol - teor de sacarose aparente do caldo

${ }^{\circ}$ Brix - teor de sólidos solúveis do caldo

O teor de açúcares redutores do caldo (AR) foi determinado por meio da equação 5 :

$A R=3,641-0,0343 \times$ pureza [5]

em que:

$\mathrm{AR}$ - teor de açúcares redutores

pureza - pureza do caldo

Os dados foram submetidos à análise de variância e, quando apresentavam significância, as médias foram comparadas pelo teste de Tukey $(5 \%)$ ou submetidas à análise de regressão conforme a natureza das variáveis envolvidas.

\section{Resultados e Discussão}

A cana-de-açúcar é considerada uma espécie altamente eficiente em conversão energética, uma vez que seu metabolismo fotossintético é do tipo $\mathrm{C} 4$, caracterizado pela eficiência na fixação de $\mathrm{CO}_{2}$. Além disso, em condições de alta luminosidade e disponibilidade de água, a espécie pode apresentar elevada produção de biomassa. Marin e Nassif (2013), 
dentre outras considerações, enfatizam que, em cenários de mudanças climáticas, o aumento na temperatura e principalmente na concentração de $\mathrm{CO}_{2}$ para a cultura da cana-de-açúcar é benéfico no que se refere às relações hídricas solo-plantaatmosfera, reduzindo o efeito do principal fator de estresse para a cultura e que o aumento na temperatura e concentração de $\mathrm{CO}_{2}$ pode aumentar as taxas de fotossíntese. Ao se analisar as condições climáticas durante o período experimental, verifica-se alta radiação solar (luminosidade), temperatura média anual favorável ao desenvolvimento da cultura e baixa precipitação, a qual foi suplementada durante todo o período pela irrigação e, mesmo em condições de estresse hídrico, a cultura apresentou bons índices de crescimento, como poderá ser observado nos resultados seguintes.

O resumo da análise das variáveis biométricas da cultura da cana-de-açúcar irrigada por gotejamento subsuperficial e submetidas ao estresse hídrico é apresentado na Tabela 1, considerando-se a altura de planta, diâmetro do colmo, número de entrenós e número de perfilhos, em quatro avaliações, durante o ciclo de cana soca de segunda folha (ressoca).

Tabela 1. Resumo da análise de variância para altura, diâmetro, número de entrenós e número de perfilhos em função de diferentes cultivares e lâminas de irrigação em cana soca de segunda folha.

\begin{tabular}{|c|c|c|c|c|c|}
\hline \multirow{3}{*}{ FV } & \multirow{3}{*}{ GL } & Altura & Diâmetro & Entrenós & Perfilhos \\
\hline & & \multicolumn{4}{|c|}{ Quadrados Médios } \\
\hline & & \multicolumn{4}{|c|}{ Primeira Avaliação } \\
\hline Lâmina & 3 & $0,478538 *$ & $0,249785^{\mathrm{ns}}$ & $8,548687 *$ & $8,691270^{\mathrm{ns}}$ \\
\hline Cultivar & 6 & $0,034323 \mathrm{~ns}$ & 3,306008 ns & 1,037388 ns & $8,378730^{\text {ns }}$ \\
\hline Lâmina*Cultivar & 18 & $0,040256^{\mathrm{ns}}$ & $3,227312^{\text {ns }}$ & 1,470837 ns & $9,264233^{\mathrm{ns}}$ \\
\hline Bloco & 2 & 0,135432 ns & 8,677701 ns & $6,456868 \mathrm{~ns}$ & $7,910476^{\mathrm{ns}}$ \\
\hline Resíduo & 54 & 0,047600 & 3,718514 & 2,162495 & 6,942575 \\
\hline \multirow[t]{2}{*}{$\mathrm{CV}(\%)$} & --- & 14,61 & 7,90 & 15,22 & 12,18 \\
\hline & & \multicolumn{4}{|c|}{ Segunda Avaliação } \\
\hline Lâmina & 3 & $1,376114 *$ & $10,500773 *$ & $7,297870 \mathrm{~ns}$ & $\begin{array}{l}138,736848 \\
*\end{array}$ \\
\hline Cultivar & 6 & $0,054275 \mathrm{~ns}$ & 5,186787 ns & 4,275222 ns & $9,878205^{\text {ns }}$ \\
\hline Lâmina*Cultivar & 18 & $0,057903 \mathrm{~ns}$ & 5,963748 ns & $2,651533^{\mathrm{ns}}$ & $8,161919^{\text {ns }}$ \\
\hline Bloco & 2 & $0,006175 \mathrm{~ns}$ & 2,890825 ns & 2,889900 ns & $64,484223 *$ \\
\hline Resíduo & 54 & 0,054698 & 4,793013 & 4,991535 & 6,782737 \\
\hline \multirow[t]{2}{*}{$\mathrm{CV}(\%)$} & --- & 10,62 & 8,76 & 13,14 & 14,39 \\
\hline & & \multicolumn{4}{|c|}{ Terceira Avaliação } \\
\hline Lâmina & 3 & $3,509927 *$ & $14,883042 *$ & $10,291728^{\mathrm{ns}}$ & $9,240725^{\text {ns }}$ \\
\hline Cultivar & 6 & $0,122936^{\mathrm{ns}}$ & $40,109588 *$ & $28,233088 *$ & 12,243463 ns \\
\hline Lâmina*Cultivar & 18 & $0,084363 \mathrm{~ns}$ & $5,194423 \mathrm{~ns}$ & $4,2001322^{\mathrm{ns}}$ & 11,696521 ns \\
\hline Bloco & 2 & $0,046537 \mathrm{~ns}$ & 5,157025 ns & 0,048443 ns & $45,056487 *$ \\
\hline Resíduo & 54 & 0,049823 & 4,977820 & 3,881313 & 13,447425 \\
\hline \multirow[t]{2}{*}{$\mathrm{CV}(\%)$} & --- & 8,08 & 8,86 & 8,31 & 21,16 \\
\hline & & \multicolumn{4}{|c|}{ Quarta Avaliação } \\
\hline Lâmina & 3 & $4,382048 *$ & $3,075903^{\mathrm{ns}}$ & $24,179823 *$ & 2,349662 ns \\
\hline Cultivar & 6 & 0,110079 ns & $9,533629 \mathrm{~ns}$ & $41,084041 *$ & 8,047622 ns \\
\hline Lâmina*Cultivar & 18 & $0,118343 *$ & 3,844997 ns & $5,441931^{\text {ns }}$ & $5,376013^{\text {ns }}$ \\
\hline Bloco & 2 & $0,008894 \mathrm{~ns}$ & $2,489944^{\mathrm{ns}}$ & $5,888443^{\mathrm{ns}}$ & $29,835904 *$ \\
\hline Resíduo & 54 & 0,060414 & 4,264074 & 5,969708 & 6,723113 \\
\hline
\end{tabular}




\begin{tabular}{llllll}
\hline CV (\%) & -- & 6,89 & 7,88 & 8,75 & 14,57
\end{tabular}

Onde: $\mathrm{CV}$ = Coeficiente de Variação, * - significativo e ns - não significativo pelo teste $\mathrm{F}$ a $5 \%$ de probabilidade.

Pela Figura 2, verifica-se que o modelo quadrático das funções indica que alturas máximas são atingidas quando se aplicam lâminas de reposição da evapotranspiração da cultura compreendidas entre 80 e $100 \%$. Isso sugere que: para se alcançar a máxima altura de plantas não é necessária a máxima reposição da evapotranspiração. É possível observar, ainda, que a cultura se desenvolveu bem no período de avaliação, chegando a atingir valores próximos a 3 metros de altura na terceira avaliação.

De acordo com Diola e Santos (2010), o crescimento em altura é contínuo até a ocorrência de alguma limitação no suprimento de água, de baixas temperaturas ou, ainda, devido ao florescimento, dependendo da responsividade de cada genótipo às diferentes condições ambientais.

Santana (2012), avaliando o comportamento de variedades melhoradas de cana-de-açúcar sob diferentes lâminas de irrigação, quanto às características agronômicas e tecnológicas em condições semiáridas do Norte de Minas Gerais, observou resposta linear de crescimento da cultura em função do aumento das lâminas de irrigação.

Em relação à quarta avaliação, a interação entre os fatores conduziu a análise para $o$ desdobramento, tendo-se verificado que o desdobramento do fator lâmina dentro de cultivares foi significativo para todas as cultivares estudadas, ou seja, cada cultivar apresentou altura diferente em função das lâminas de irrigação.

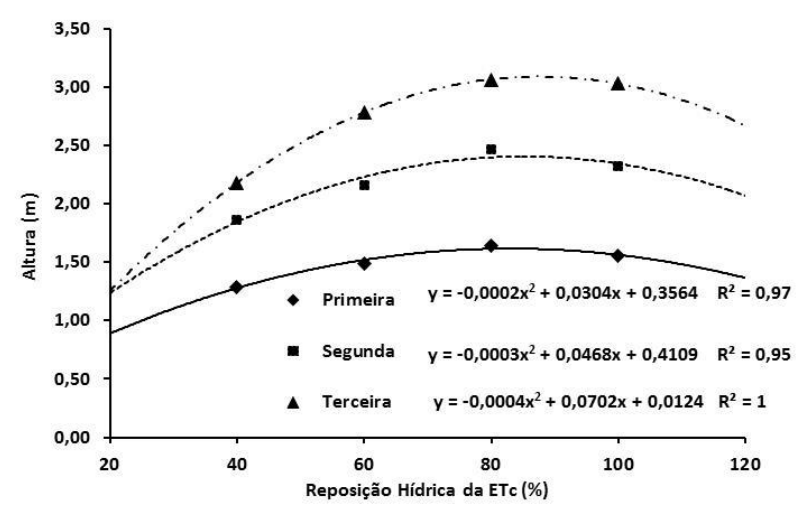

Figura 2. Altura média das cultivares em função das lâminas de reposição hídrica da ETc nas $1^{\mathrm{a}}$, $2^{\mathrm{a}}$ e $3^{\mathrm{a}}$ avaliações.

A Figura 3 apresenta o gráfico e as funções quadráticas geradas durante a análise. Verifica-se que valores de ETc próximos a $80 \%$ são suficientes para atingir a máxima altura, com destaque para as variedades RB 96-1003 e RB 943206.

Diferenças na altura de plantas das cultivares podem ser um indicativo de tolerância ou suscetibilidade da cana-de-açúcar ao déficit hídrico (Silva et al., 2008a; Machado et al., 2009). 


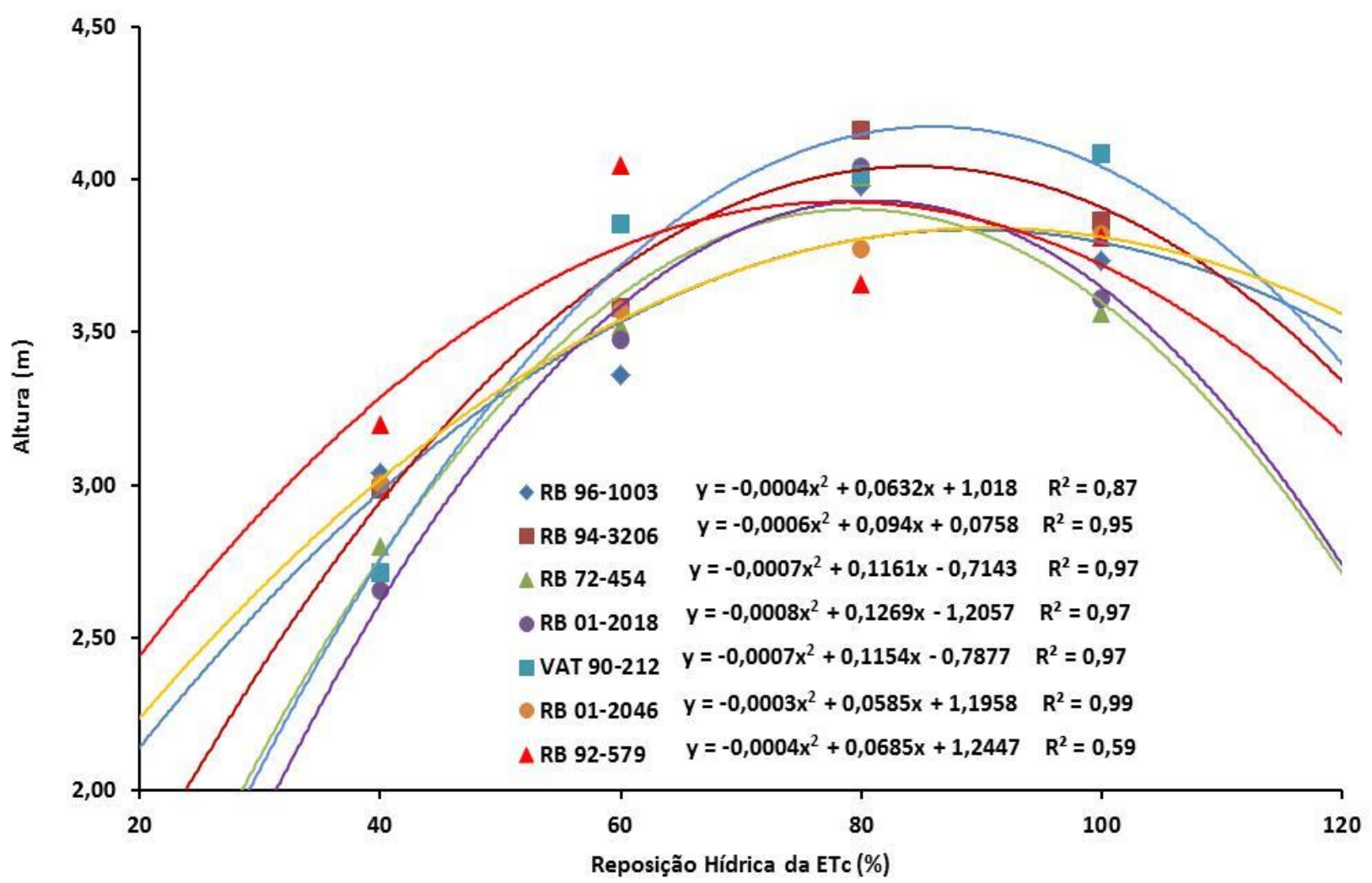

Figura 3. Altura média das cultivares em função das lâminas de reposição hídrica da ETc na $4^{\mathrm{a}}$ avaliação (colheita).

Em relação à variável diâmetro do colmo, verificou-se que não houve interação entre os fatores em nenhuma das quatro avaliações realizadas (Tabela 1). Contudo, o fator lâmina de reposição hídrica da evapotranspiração da cultura, isolado, foi significativo nas segunda e terceira avaliações (Figura 4), sendo o modelo quadrático o de melhor ajuste para explicar as variáveis. $\mathrm{O}$ fator cultivares, isolado, foi significativo na terceira avaliação (Tabela 2). A comparação das médias demonstrou que a cultivar RB 92-579 com, aproximadamente, $21,80 \mathrm{~mm}$ apresentou o menor diâmetro, assemelhando-se apenas à cultivar RB 94-3206.

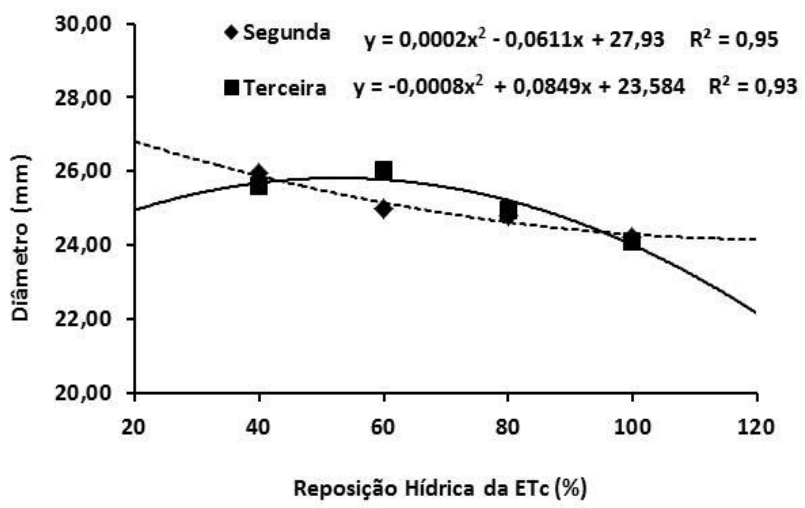

Figura 4. Diâmetro médio dos colmos de cana-deaçúcar nas $2^{\mathrm{a}}$ e $3^{\mathrm{a}}$ avaliações.

O diâmetro do colmo é uma característica que apresenta pouca influência das lâminas de irrigação, estando mais relacionada às características genéticas de cada cultivar. Oliveira et al. (2010), ao avaliarem variedades cultivadas sob irrigação, observaram pouca influência na variável diâmetro do colmo.

Tabela 2. Diâmetro médio das cultivares na $3^{\mathrm{a}}$ avaliação.

\begin{tabular}{cc}
\hline Cultivares & Diâmetro $(\mathrm{mm})$ \\
\hline RB 96-1003 & $25,525833 \mathrm{ab}$ \\
RB 94-3206 & $24,546667 \mathrm{bc}$ \\
RB 72-454 & $24,859167 \mathrm{ab}$ \\
RB 01-2018 & $26,818333 \mathrm{ab}$ \\
VAT 90-212 & $25,201667 \mathrm{ab}$ \\
RB 01-2046 & $27,483333 \mathrm{a}$ \\
RB 92-579 & $21,797500 \mathrm{c}$ \\
\hline DMS & 2,7896 \\
\hline
\end{tabular}

Médias seguidas por letras iguais não diferem entre si pelo teste de Tukey a $5 \%$ de probabilidade. 
O diâmetro do colmo é uma característica que apresenta pouca influência das lâminas de irrigação, estando mais relacionado às características genéticas de cada cultivar. Oliveira et al. (2010), ao avaliarem variedades cultivadas sob irrigação, observaram pouca influência na variável diâmetro do colmo.

Os resultados também corroboram com Oliveira et al. (2011) que, avaliando os padrões de crescimento e de produção de variedades de canade-açúcar submetidas a diferentes níveis de adubação com nitrogênio e potássio e diferentes restrições na irrigação (menores lâminas de irrigação) em cana soca de segunda folha, observaram que dentre as variáveis estudadas em análise de crescimento, o diâmetro do colmo é a que apresenta menor variação, já que depende das características genéticas da variedade, do número de perfilhos, do espaçamento utilizado, da área foliar e das condições ambientais.

O número de entrenós das cultivares, assim como ocorreu com o diâmetro, não foi afetado pela interação dos fatores cultivares e lâminas de reposição hídrica em nenhuma das quatro avaliações realizadas, sendo que, nas terceira e quarta avaliações, apresentou diferenças apenas em função das cultivares (Tabela 3 ). Nota-se que as cultivares RB 94-3206, RB 01-2018 e VAT 90212 se destacam nas duas épocas de avaliação como as de maior número de entrenós; já as cultivares RB 96-1003 e RB 01-2046 se apresentam com os menores números de entrenós nas duas avaliações. De acordo com Arantes (2012), o número de entrenós se torna dependente do desenvolvimento dos perfilhos, sendo que a emissão de novos entrenós é variável, podendo ser inibido pelos estresses ambientais, seja hídrico ou nutricional.

Tabela 3. Número médio de entrenós das cultivares nas $3^{\mathrm{a}}$ e $4^{\mathrm{a}}$ avaliações.

\begin{tabular}{lcl}
\hline \multicolumn{1}{c}{ Cultivares } & $\begin{array}{c}\text { Terceira } \\
\text { avaliação }\end{array}$ & \multicolumn{1}{c}{$\begin{array}{c}\text { Quarta } \\
\text { avaliação }\end{array}$} \\
\hline RB 96-1003 & $21,051667 \mathrm{c}$ & \multicolumn{2}{c}{$24,71833 \mathrm{c}$} \\
RB 94-3206 & $25,719167 \mathrm{a}$ & $30,55250 \mathrm{a}$ \\
RB 72-454 & $23,886667 \mathrm{ab}$ & $27,47000 \mathrm{bc}$ \\
RB 01-2018 & $25,135000 \mathrm{ab}$ & $29,38500 \mathrm{ab}$ \\
VAT 90-212 & $24,051667 \mathrm{ab}$ & 27,63500 \\
& & abc \\
RB 01-2046 & $22,940000 \mathrm{bc}$ & $27,19000 \mathrm{bc}$ \\
RB 92-579 & $23,218333 \mathrm{bc}$ & $28,55167 \mathrm{ab}$ \\
\hline
\end{tabular}

\section{DMS}

2,4633

3,0549

Médias seguidas por letras iguais, na coluna, não diferem entre si pelo teste de Tukey a $5 \%$ de probabilidade.

O fator lâmina, isolado, mostrou significância nas primeira e quarta avaliações, conforme pode ser verificado na Figura 5.

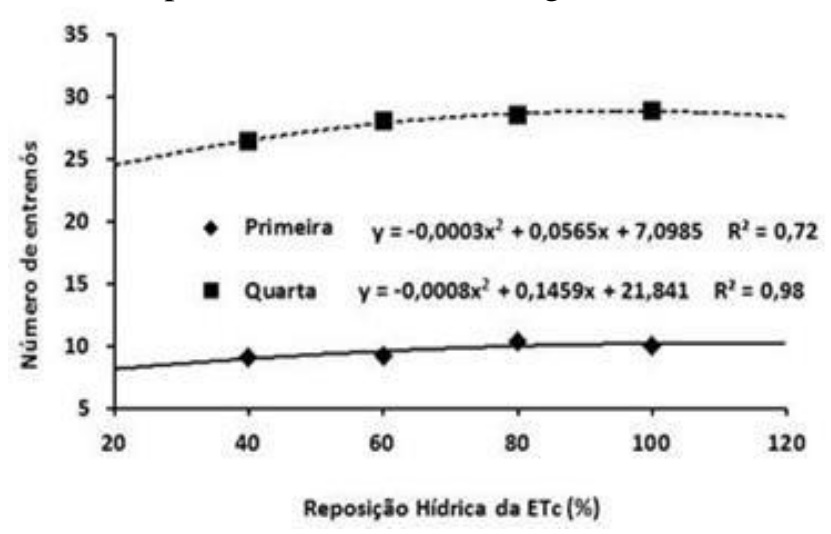

Figura 5. Número médio de entrenós nas $1^{\mathrm{a}}$ e $4^{\mathrm{a}}$ avaliações das cultivares em função das lâminas de reposição hídrica da ETc.

Pedrosa et al. (2005), estudando o comportamento morfofisiológico da variedade da cana-de-açúcar SP-79101, em soqueira, submetidas a três laminas de irrigação e adubação, observaram que houve efeito significativo para o fator irrigação e concluíram que o número de internódios por planta alcançou valor máximo $(23,40)$ com a maior lâmina aplicada $(1.164 \mathrm{~mm})$ e o menor valor $(19,10)$ com lâmina menor $(807$ $\mathrm{mm})$.

Em relação ao número de perfilhos por metro linear, não houve interação significativa entre as cultivares e as lâminas de reposição hídrica da ETc em nenhuma das épocas avaliadas. Apenas na segunda avaliação, observou-se efeito de lâminas (Figura 6).

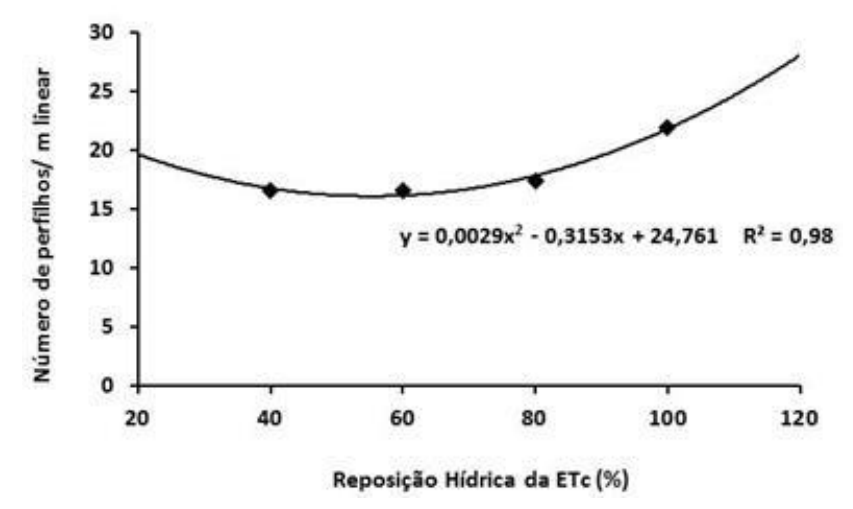


Figura 6. Número médio de perfilhos por metro linear na $2^{\mathrm{a}}$ avaliação das cultivares.

As pequenas diferenças encontradas no número de perfilhos se devem ao fato de que, na fase de maior perfilhamento da cultura, as cultivares estavam recebendo a mesma lâmina de irrigação. Silva et al. (2008b) relatam que períodos de déficit hídrico podem ocorrer durante todo o ciclo, mas seus efeitos na produtividade variam em função da fase do ciclo fenológico da cultura. A fase de perfilhamento é a mais crítica em relação à demanda hídrica (Inman-Bamber e Smith, 2005) e, por isso, no experimento, as plantas só foram submetidas ao estresse após este período, pois a falta de água nesta fase inviabilizaria o estudo. De acordo com Marafon (2012), a cana-de-açúcar perfilha nos primeiros meses após a rebrota, e esse perfilhamento se intensifica à medida que as condições de temperatura e de disponibilidade hídrica são favorecidas. Caso ocorra estresse hídrico durante a germinação e o perfilhamento, haverá reduções na condutância estomática, taxa de fotossíntese, número e tamanho dos perfilhos e acúmulo de biomassa (Zhao et al., 2010).

Os resultados corroboram com Almeida et al. (2008) que, avaliando os padrões de crescimento de cultivares de cana-de-açúcar em regimes diferentes de disponibilidade hídrica, observaram que o aumento do perfilhamento acentua-se do início da emergência até 60 dias na cana soca.
Silva et al. (2012a), avaliando os parâmetros biométricos da parte aérea da cana-deaçúcar irrigada no Vale do Submédio São Francisco, observaram que a dinâmica do número de perfilhos, em cana soca, é caracterizada por um período de aumento do número de perfilhos, que ocorre até 96 dias após a colheita e por um segundo período, compreendido entre 96 e 154 dias após a colheita, no qual há o perfilhamento máximo e a estabilização desse número, apresentando também uma fase de rápida senescência.

Ainda, os valores encontrados para número de perfilhos é similar ao encontrado por Silva et al. (2012a), que, avaliando o número de perfilhos da cultivar RB 92-579, constataram números elevados de perfilhos industrializáveis nos sistemas de irrigação $\left(15,2\right.$ perfilhos $\left./ \mathrm{m}^{2}\right)$.

Aliada às informações biométricas, procedeu-se a avaliação das variáveis tecnológicas do caldo da cana-de-açúcar. De acordo com a Tabela 4, as variáveis analisadas: teor de sólidos solúveis - ${ }^{\circ}$ Brix, fibra industrial na cana-de-açúcar - Fibra (\%), pureza do caldo - PRZ (\%), percentagem de açúcar bruto - PCC (\%) e açúcares redutores - $\mathrm{AR}$ (\%) não foram influenciados pela interação entre os fatores lâminas de reposição hídrica e cultivares. Contudo, o ${ }^{\circ}$ Brix e PCC demonstraram alterações significativas em função das lâminas de reposição hídrica da ETc.

Tabela 4. Resumo da análise de variância da qualidade tecnológica do caldo da cana-de-açúcar.

\begin{tabular}{lcccccc}
\hline \multirow{2}{*}{ FV } & \multirow{2}{*}{ GL } & ${ }^{\circ}$ Brix & Fibra & PZA & PCC & AR \\
\cline { 3 - 7 } & & \multicolumn{5}{c}{ Quadrados Médios } \\
\hline Lâmina & 3 & $3,933071 *$ & $0,564392 \mathrm{~ns}$ & $20,50434 \mathrm{~ns}$ & $4,287730 *$ & $0,006074 \mathrm{~ns}$ \\
Cultivar & 6 & $0,514015 \mathrm{~ns}$ & $0,189341 \mathrm{~ns}$ & $14,53796 \mathrm{~ns}$ & $0,585583 \mathrm{~ns}$ & $0,010043 \mathrm{~ns}$ \\
Lâmina*Cultivar & 18 & $1,216766 \mathrm{~ns}$ & $0,235181 \mathrm{~ns}$ & $10,78305 \mathrm{~ns}$ & $0,950746 \mathrm{~ns}$ & $0,010768 \mathrm{~ns}$ \\
\hline Bloco & 2 & $14,76798 *$ & $0,126175 \mathrm{~ns}$ & $97,03800 *$ & $10,94638 *$ & $0,013433 \mathrm{~ns}$ \\
\hline Resíduo & 54 & 0,986701 & 0,387527 & 20,361201 & 0,617317 & 0,006736 \\
\hline CV $(\%)$ & --- & 4,55 & 4,20 & 5,42 & 5,36 & 10,66 \\
\hline
\end{tabular}


Observa-se, na Figura 7 , que o ${ }^{\circ}$ Brix apresentou redução com a aplicação de maiores lâminas de irrigação, sendo o comportamento desta variável representado por uma equação linear. Maiores lâminas de irrigação pressupõem maior diluição dos sólidos solúveis e, por isso, essa variável tende a diminuir com a reposição hídrica. Scarpari e Beauclair (2008) observaram que, em áreas que apresentam maior disponibilidade hídrica, os valores de ${ }^{\circ}$ Brix são menores devido à diluição dos açúcares. Em estudo desenvolvido com o objetivo de avaliar o desempenho produtivo e qualitativo da cana-deaçúcar irrigada por gotejamento subsuperficial com efluente de estação de tratamento de esgoto, Deon et al. (2010) verificaram diminuição significativa do teor de sólidos solúveis totais no caldo da cana com a irrigação na primeira soca. Os resultados aqui encontrados também corroboram com Oliveira et al. (2011) que, ao avaliarem a produtividade de colmos e de açúcar, a eficiência de uso da água e os atributos tecnológicos de cinco variedades de cana-deaçúcar de maturação precoce e seis de maturação média à tardia, submetidas ao regime de sequeiro $(1.141,4 \mathrm{~mm})$ e à irrigação plena $(1.396,6 \mathrm{~mm})$, observaram decréscimo de 1,1 grau com o uso da irrigação. Simões et al. (2015), ao avaliarem as respostas de variáveis fisiológicas e tecnológicas da cana-de-açúcar a diferentes sistemas de irrigação, concluíram que o sistema de irrigação por sulco, em solo argiloso, reduziu os graus Brix da cultura.

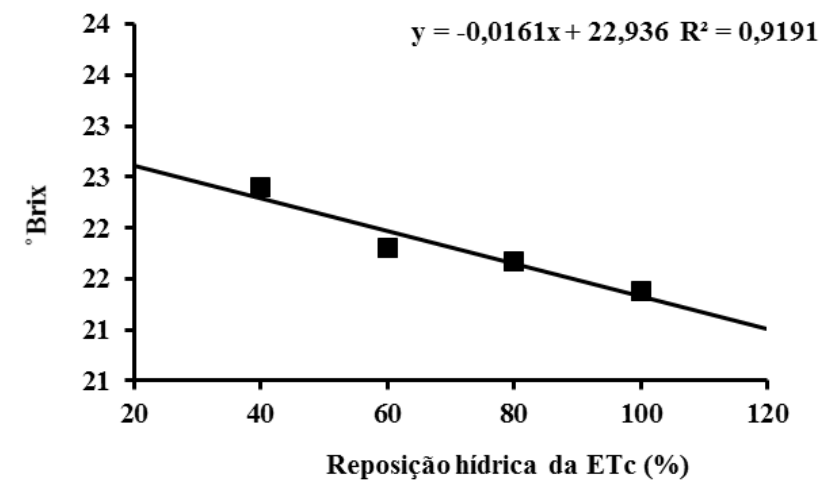

Figura 7. Graus Brix médios das cultivares em função das diferentes lâminas de reposição hídrica da ETc em cana soca de segunda folha (ressoca).

Apesar da redução nos teores de ${ }^{\circ}$ Brix, os valores encontrados na maior disponibilidade hídrica $(100 \%$ da evapotranspiração) são superiores a $18^{\circ}$ Brix, sendo considerados satisfatórios por Marques et al. (2001).
A fibra industrial da cana-de-açúcar não apresentou diferenças estatísticas, sendo a média encontrada de 14,83\%. Este valor é superior ao encontrado no trabalho de Deon et al. (2010), que observaram valores de $11,60 \%$ em cana soca de segunda folha. Por outro lado, os resultados corroboram com Simões et al. (2015) que observaram valores de 14,9 e $16,6 \%$ de fibra em cana soca de primeira e segunda folha, respectivamente, em estudo realizado em Juazeiro, BA, cujas condições climáticas são muitos similiares a este estudo, uma vez que os municípios são vizinhos. No trabalho de Oliveira et al. (2011), o percentual de fibra encontrado para condições de sequeiro foi elevado $(15,4 \%)$. O resultado ora encontrado é superior à recomendação (11 a 13\%) de Ripoli e Ripoli (2004), o que pode gerar redução na extração do caldo na moenda. Contudo, Vian (2013) ressalta que é necessário considerar que variedades de cana com baixos teores de fibra são mais suscetíveis a danos mecânicos ocasionados no corte e transporte, o que favorece a contaminação $\mathrm{e}$ as perdas na indústria e que, quando a cana apresenta baixo percentual de fibra, ela se torna mais suscetível ao acamamento e à quebra pelo vento, o que a faz perder mais açúcar na água de lavagem.

Há de se considerar, ainda, que atualmente o melhoramento genético da cana-de-açúcar está priorizando a produção de fibra para fins energéticos (Matsuoka et al., 2012).

A análise da pureza do caldo resultou em $83,26 \%$, valor considerado abaixo do mínimo indicado por Ripoli e Ripoli (2004) que recomendam que a pureza seja superior a $85 \%$. Porém, o CONSECANA (2006) relata, em suas normas operacionais de determinação da qualidade da cana-de-açúcar, que a unidade industrial só poderá recusar o recebimento de carregamentos com pureza do caldo abaixo de $75 \%$.

Em relação à percentagem de açúcar bruto - PCC (\%), observou-se que apenas o fator lâminas de reposição hídrica da ETc foi significativo. Nota-se redução na percentagem de açúcar bruto à medida que se aumenta a disponibilidade hídrica do solo, dentro do intervalo estudado, uma vez que o melhor ajuste para as curvas foi obtido pela equação polinomial quadrática (Figura 8). Ainda que tenha ocorrido redução do PCC com o aumento das lâminas de reposição hídrica, mesmo na maior lâmina de reposição (100\%), os valores encontrados são elevados e atendem à recomendação de Ripoli e 
Ripoli (2004), que estabelecem, como ideais, valores superiores a $14 \%$. Trabalho desenvolvido por Muraro et al. (2009) indicou que o acúmulo de sacarose é extremamente influenciado pela disponibilidade hídrica, sendo o excesso de água desfavorável, pois atua como fator diluente da sacarose que estava presente no colmo das plantas.

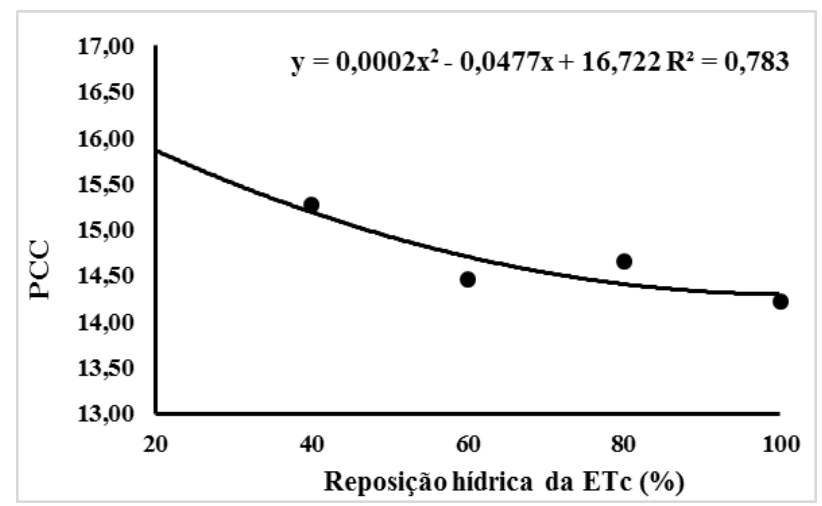

Figura 8. Porcentagem de açúcar bruto (PCC) médio das cultivares em função da reposição hídrica da ETc em cana soca de segunda folha (ressoca).

A média de açúcares redutores encontrada foi de 0,77. Apesar de este valor atender à recomendação de Ripoli e Ripoli (2004), pois é inferior a $0,8 \%$, não se observou maior pureza do caldo, devendo-se esta baixa relação a outros fatores além da presença de glicose e frutose no caldo. Oliveira et al. (2012) relatam que a característica pureza do caldo da cana-de-açúcar está diretamente relacionada com a qualidade da matéria-prima, e sofre influência das impurezas minerais e vegetais que são adicionadas à cana no momento da colheita. Simões et al. (2015) também encontraram valores inferiores a $0,8 \% \mathrm{em}$ cana soca de segunda folha.

O cultivo da cana-de-açúcar com lâminas reduzidas de irrigação apresenta-se, desta forma, como uma possibilidade para áreas agrícolas da região Semiárida, notadamente, no Submédio do Vale do São Francisco, onde a expansão do cultivo pode ser potencializada para os perímetros irrigados da região. Entretanto, a resposta à tolerância ao estresse hídrico é dependente da cultivar, do manejo adotado na irrigação, do sistema de cultivo e de outros aspectos relacionados ao sistema de cultivo da cana-deaçúcar.

Observa-se que as cultivares responderam positivamente a menores lâminas de reposição, o que pode sugerir o que o Kc sugerido pela FAO $(0,4$ na fase inicial, 1,25 na fase de maior demanda hídrica e 0,7 na fase final) não seja o mais adequado para a cultura nas condições edafoclimáticas do Vale do Submédio São Francisco. Em estudo realizado por Silva et al. (2012b) com o objetivo de determinar o requerimento hídrico e o coeficiente de cultura (Kc) da canade-açúcar irrigada durante o ciclo de soca, variedade RB 92-579, na região semiárida do Submédio do Vale do São Francisco foi constado que o requerimento hídrico total da cana-de-açúcar foi de $1710 \mathrm{~mm}$, e o Kc atingiu o valor médio de 1,10 na fase de crescimento máximo, valor este inferior ao recomendado pela FAO.

Neste processo de identificação de cultivares de cana-de-açúcar mais adaptadas às condições edafoclimáticas da região, é relevante a continuidade de pesquisas com outras cultivares, utilizando-se outras variáveis produtivas a fim de que a atividade possa alcançar maior sucesso.

\section{Conclusões}

a) A altura é um dos principais caracteres relacionados à produtividade da cana-deaçúcar e a máxima altura pode ser atingida com menores lâminas de reposição hídrica, o que representa maior economia em cenários de menor disponibilidade hídrica. As cultivares RB 96-1003 e RB 94-3206 se destacaram com lâminas de reposição hídrica de $80 \%$ da ETc.

b) O diâmetro do colmo e o número de entrenós são características mais relacionadas com o componente genético da cultivar.

c) O número de perfilhos, em cana soca de segunda folha, é pouco influenciado pelas lâminas de irrigação se o estresse hídrico se iniciar após 90 dias da colheita da cana soca.

d) $\mathrm{O}^{\circ}$ Brix e a porcentagem de açúcar bruto PCC reduzem com o aumento da disponibilidade hídrica do solo. Contudo, mesmo com $100 \%$ de reposição hídrica, os valores destas características estão em conformidade com a recomendação mínima.

e) A qualidade tecnológica foi preservada nas cultivares com menores lâminas de irrigação.

\section{Agradecimento}

Ao Banco do Nordeste do Brasil S. A. (BNB), pelo apoio financeiro à pesquisa. 


\section{Referências}

Allen, R.G., Pereira, L.S., Raes, D., Smith, M., 1998. Crop evapotranspiration: guidelines for computing crop water requirements. FAO, Rome. (FAO. Irrigation and Drainage Paper, 56).

Almeida, A.C.S., Souza, J.L., Teodoro, I., Barbosa, G.V.S., Moura Filho, G., Ferreira Júnior, R.A., 2008. Desenvolvimento vegetativo e produção de variedades de cana-de-açúcar em relação à disponibilidade hídrica e unidades térmicas. Ciência e Agrotecnologia 32, 14411448.

Arantes, M.T., 2012. Potencial produtivo de cultivares de cana-de-açúcar sob os manejos irrigado e sequeiro. Dissertação (Mestrado). Botucatu, UNESP.

Araújo, S.M.S., 2011. A região semiárida do nordeste do Brasil: questões ambientais e possibilidades de uso sustentável dos recursos. Rios Eletrônica - Revista Científica da FASETE 5, 89-98.

Assis, P.C.O., Lacerda, R.D., Azevedo, H.M., Dantas Neto, J., Farias, C.H.A., 2004. Resposta dos parâmetros tecnológicos da cana-de-açúcar a diferentes lâminas de irrigação e adubação. Revista de Biologia e Ciências da Terra 4, 337342.

Azad, M.A.S., Ancev, T., Hernández-Sancho, F., 2015. Efficient water use for sustainable irrigation industry. Water Resources Management 29, 1683 -1696.

Bachchhav, S.M., 2005. Fertigation technology for increasing sugarcane production. Indian Journal of Fertilisers 1, 85-92.

Basnayake, J., Jackson, P.A., Inman-Bamber, N.G., Lakshmanan, P., 2012. Sugarcane for water-limited environments. Genetic variation in cane yield and sugar content in response to water stress. Journal of Experimental Botany 63, 6023-6033.

Caldas, C., 2005. Teoria Básica das Análises Sucroalcooleiras. Central Analítica, Maceió.

Camargo, I.A., 2013. Sistema antioxidante de cana-de-açúcar em resposta à seca. Dissertação (Mestrado). Piracicaba, CENA.

Carvalho, A.L., Menezes, R.S.C., Nóbrega, R.S., Pinto, A.S., Ometto, J.P.H.B., Randow, C., Giarolla, A., 2015. Impact of climate changes on potential sugarcane yield in Pernambuco, northeastern region of Brazil. Renewable Energy 78, 26-34.

Carvalho, C.M., Azevedo, H.M., Dantas Neto, J., Farias, C.H.A., Silva, C.T.S., Gomes Filho,
R.R.G., 2009. Rendimento de açúcar e álcool da cana-de-açúcar submetida a diferentes níveis de irrigação. Revista Brasileira de Ciências Agrárias 4, 72-77.

CONAB. Companhia Nacional de Abastecimento, 2015. Acompanhamento de safra brasileira: cana-de-açúcar, primeiro levantamento, abril/2015. Brasília.

CONSECANA. Conselho dos Produtores de Cana-de-açúcar, Açúcar, Álcool do Estado de São Paulo, 2006. Manual de Instruções, 5 ed. CONSECANA, Piracicaba.

Deon, M.D., Gomes, T.M., Melfi, A.J., Montes, C.R., Silva, E., 2010. Produtividade e qualidade da cana-de-açúcar irrigada com efluente de estação de tratamento de esgoto. Pesquisa Agropecuária Brasileira 45, 1149-1156.

Diola, V., Santos, F., 2010. Fisiologia, in: Santos, F., Borém, A., Caldas, C. (Eds.), Cana-deaçúcar: bioenergia, açúcar e álcool: tecnologias e perspectivas. UFV, Viçosa, pp. 25-49.

Doorenbos, J., Kassam, A.H., 1979. Yield response to water. FAO, Rome.

EMBRAPA. Empresa Brasileira de Pesquisa Agropecuária, 2006. Sistema Brasileiro de Classificação de Solos. 2 ed. Embrapa Solos, Rio de Janeiro; Sistema de Produção de Informação, Brasília.

EMBRAPA. Empresa Brasileira de Pesquisa Agropecuária, 2012. Proposta de atualização da segunda edição do sistema brasileiro de classificação de solos: ano 2012. Embrapa Solos, Rio de Janeiro. (Embrapa Solos. Documentos, 140).

Farias, C.H.A., Fernandes, P.D., Azevedo, H.M., Dantas Neto, J., 2008. Índices de crescimento da cana-de-açúcar irrigada e de sequeiro no Estado da Paraíba. Revista Brasileira de Engenharia Agrícola e Ambiental 12, 356-362.

Figueiredo, I.C., Maciel, B.F., Marques, M.O., 2008. A qualidade da cana-de-açúcar como matéria-prima para produção de álcool. Nucleus 82-93. Edição Especial.

Gouvêa, J.R.F., Sentelhas, P.C., Gazzola, S.T., Santos, M.C., 2009. Climate changes and technological advances: impacts on sugarcane productivity in tropical southern Brazil. Scientia Agricola 66, 593-605.

Hemaprabha, G., Swapna, S., Lavanya, D.L., Sajtha, B., Venkataramana, S., 2013. Evaluation of drought tolerance potential of elite genotypes and progenies of sugarcane (Saccharum sp hybrids). Sugar Tech 15, 9-16.

Holanda, L.A., Santos, C.M., Sampaio Neto, G.D., Sousa, A.P., Silva, M.A., 2014. Variáveis morfológicas da cana-de-açúcar em função do

Oliveira; A. R. O.; Braga, M. B.; Walker, A. M. 
regime hídrico durante o desenvolvimento inicial. Irriga 19, 573-584.

Horii, J., 2004. A Cana-de-açúcar como Matériaprima. ESALQ - Departamento de Agroindústria, Alimentos e Nutrição, Piracicaba.

Hussain, K., Majeed, A., Nawaz, K., Afghan, S., Ali, K., Lin, F., Zafar, Z., Raza, G., 2010. Comparative study of subsurface drip irrigation and flood irrigation systems for quality and yield of sugarcane. African Journal of Agricultural Research 5, 3026-3034.

Inman-Bamber, N.G., Smith, D.M., 2005. Water relations in sugarcane and response to water deficits. Field Crops Research 92, 185-202.

Leme Filho, J.R.A., 2005. Estudo comparativo dos métodos de determinação e de estimativa dos teores de fibra de açúcares redutores em cana-de-açúcar (Saccharum spp.). Dissertação (Mestrado). Piracicaba, ESALQ.

Lima, U., Basso, L.C. Amorim, H.V., 2001. Produção de etanol, in: Lima, U.A. (Coord.), Processos Fermentativos e Enzimáticos. Edgard Blücher, São Paulo, pp. 1-43.

Machado, R.S., Ribeiro, R.V., Marchiori, P.E.R., Machado, D.F.S.P., Machado, E.C., Landel, M.G.A., 2009. Biometric and physiological responses to water deficit in sugarcane at different phenological stages. Pesquisa Agropecuária Brasileira 44, 1575-1582.

Marafon, A.C., 2012. Análise quantitativa de crescimento em cana-de-açúcar: uma introdução ao procedimento prático. Embrapa Tabuleiros Costeiros, Aracaju. (Embrapa Tabuleiros Costeiros. Documentos, 168).

Marin, F., Nassif, D.S.P., 2013. Mudanças climáticas e a cana-de-açúcar no Brasil: fisiologia, conjuntura e cenário futuro. Revista Brasileira de Engenharia Agrícola e Ambiental 17, 232-239.

Marques, M.O., Mutton, M.A., Nogueira, T.A.R., Tasso Junior, L.C., Nogueira, G.A., Bernardi, J.H., 2008. Tecnologia na Agroindústria Canavieira. FCAV, Jaboticabal.

Marques, M.O., Marques, T.A., Tasso Júnior, L.C., 2001. Tecnologia do Açúcar: produção e industrialização da cana-de-açúcar. FUNEP, Jaboticabal.

Matsuoka, S., Bressiani, J., Maccheroni, W., Fouto, I., 2012. Bioenergia da Cana., in: Santos, F., Borém, A., Caldas, C. (Eds.), Cana-deaçúcar: bioenergia, açúcar e álcool. 2 ed. UFV, Viçosa, pp. 487-517.

Muraro, G.B., Rossi Junior, P., Oliveira, V.C., Granzotto, P.M.C., Schogor, A.L.B., 2009. Efeito da idade de corte sobre a composição bromatológica e as características da silagem de cana-de-açúcar plantada em dois espaçamentos e três idades de corte. Revista Brasileira de Zootecnia 38, 1525-1531.

Oliveira, E.C.A., 2010. Crescimento e acúmulo de matéria seca em variedades de cana-de-açúcar cultivadas sob irrigação plena. Revista Brasileira de Engenharia Agrícola Ambiental 14, 951-960.

Oliveira, E.C.A., Freire, F.J., Oliveira, A.C., Simões Neto, D.E., Rocha, A.T., Carvalho, L.A., 2011. Produtividade, eficiência de uso da água e qualidade tecnológica de cana-de-açúcar submetida a diferentes regimes hídricos. Pesquisa Agropecuária Brasileira 46, 617-625.

Oliveira, F.M., Aspiazú, I., Kondo, M.K., Borges, I.D., Pegoraro, R.F., Vianna, E.J., 2012. Avaliação tecnológica de variedades de canade-açúcar influenciadas por diferentes adubações e supressões de irrigação. Revista Ceres 59, 832-840.

Pedrosa, R.M.B., Santos, J.S., Albuquerque, W.G., Farias, C.H.A., Azevedo, H.M., Dantas Neto, J., 2005. Avaliação dos parâmetros dos colmos da cana-de-açúcar, segunda folha, submetida a níveis de irrigação e adubação. Revista de Biologia e Ciências da Terra 5, 1-5.

Pincelli, R.P., 2010. Tolerância à deficiência hídrica em cultivares de cana-de-açúcar avaliada por meio de variáveis morfofisiológicas. Dissertação (Mestrado). Botucatu, UNESP.

Pincelli, R.P. Silva, M.A., 2012. Alterações morfológicas foliares em cultivares de cana-deaçúcar em resposta à deficiência hídrica. Bioscience Journal 28, 546-556.

Pires, R.C.D., Barbosa, E., Arruda, F., Sakai, E., Araujo da Silva, T., 2014. Effects of subsurface drip irrigation and different planting arrangements on the yields and technological quality of sugarcane. Journal of Irrigation and Drainage Engineering 140, 1-6.

RIDESA. Rede Interuniversitária para o Desenvolvimento do Setor Sucroalcooleiro, 2010. Catálogo nacional de variedades "RB" de cana-de-açúcar, Curitiba: Rede Interuniversitária para o Desenvolvimento do Setor Sucroalcooleiro. Curitiba.

Ripoli, T.C.C., Ripoli, M.L.C., 2004. Biomassa de Cana-de-açúcar: colheita, energia e ambiente. Barros \& Marques Editoração Eletrônica, Piracicaba.

Santana, P.B., 2012. Desempenho agronômico e tecnológico de variedades de cana-de-açúcar submetidas a diferentes lâminas de irrigação no Norte de Minas Gerais. Dissertação (Mestrado) Janaúba, UNIMONTES. 
Santos, R.B.dos, 2011. Cultivares de cana-deaçúcar submetido à restrição hídrica. Dissertação (Mestrado). São Crisóvão, UFS.

Scarpari, M.S., Beauclair, E.G.F., 2008. Variação espaço-temporal do índice de área foliar e brix em cana-de-açúcar. Bragantia 67, 35-41.

Silva, M.A., Soares, A.B., Landell, M.G.A., Campana, M.P., 2008a. Agronomic performance of sugarcane families in response to water stress. Bragantia 67, 656-661.

Silva, M.A., Silva, J.A.G., Enciso, J., Sharma, V., Jifon, J., 2008b. Yield components as indicators of drought tolerance of sugarcane. Scientia Agricola 65, 620-627.

Silva, T.G.F., Moura, M.S.B., Zolnier, S., Carmo, J.F.A., Souza, L.S.B., 2012a. Biometria da parte aérea da cana soca irrigada no Submédio do Vale do São Francisco. Revista Ciência Agronômica 43, 500-509.

Silva, T.G.F., Moura, M.S.B., Zolnier, S., Soares, J.M., Vieira, V.J.S., Gomes Júnior, W.F., 2012b. Requerimento hídrico e coeficiente de cultura da cana-de-açúcar irrigada no semiárido brasileiro. Revista Brasileira de Engenharia Agrícola e Ambiental 16, 64-71.

Simões, W.L., Calgaro, M., Coelho, D.S., Souza, M.A., Lima, J.A., 2015. Respostas de variáveis fisiológicas e tecnológicas da cana-de-açúcar a diferentes sistemas de irrigação. Revista Ciência Agronômica 46, 11-20.

Vasconcelos, J.R., 2013. Cana-de-açúcar: crescimento, maturação e distribuição de energia. Dissertação (Mestrado) Presidente Prudente, UNOESTE.

Vian, C.E.F., 2013. Qualidade de matéria-prima, in Embrapa. Árvore do Conhecimento: cana-deaçúcar.

Disponível:

http://www.agencia.cnptia.embrapa.br/gestor/ca na-de-

cucar/arvore/CONTAG01_138_2212200615484

2.html. Acesso: 20 mar. e 2015.

Wiedenfeld, R.P., 2000. Water stress during different sugarcane growth periods on yield and response to $\mathrm{N}$ fertilization. Agricultural Water Management 43, 173-182.

Zhao, D., Glaz, B., Comstock, J.C., 2010. Sugarcane response to water-deficit stress during early growth on organic and sand soils. American Journal of Agricultural and Biological Sciences 5, 403-414.

Zhao, D., Glaz, B., Comstock, J.C., 2013. Sugarcane leaf photosynthesis and growth characters during development of water-deficit stress. Crop Science 53, 1066-1075. 